\title{
New Diagnostics for Mycobacterium tuberculosis
}

\author{
Michaela Lucas ${ }^{1,2}$, Andrew Lucas ${ }^{1}$ and Silvana Gaudieri1 ${ }^{1,3}$ \\ ${ }^{1}$ Institute for Immunology and Infectious Diseases, Murdoch University, \\ Perth, Western Australia, \\ ${ }^{2}$ Department of Health, Perth, Western Australia, \\ ${ }^{3}$ School of Anatomy and Human Biology and Centre for Forensic Science, \\ University of Western Australia, Perth, Western Australia, \\ Australia
}

\section{Introduction}

\subsection{Tuberculosis as a global health issue and the need for reliable diagnostics in primary care settings}

Mycobacterium tuberculosis (Mtb) infection is one of the leading causes of morbidity and mortality worldwide with an estimated one third of the world's population infected by Mtb resulting in about two million deaths per year (Lonnroth and Raviglione, 2008; Wallis et al., 2010). Developing countries are burdened with the highest levels of Mtb infections and conversely have the lowest financial resources available to improve this situation (Figures 1 and 2). High rates of infection are associated with poverty, low levels of public hygiene and often with a high prevalence of HIV+ individuals who are at particular risk of infection, all factors that contribute to an uncontrolled spread of Mtb infection (Corbett et al., 2006; Wright et al., 2009).

Mtb can be spread from person to person via droplet nuclei that contain Mtb organisms. Droplet nuclei are primarily produced when people with pulmonary Mtb cough or sneeze and these particles can remain in the air for long periods of time. If inhaled, these droplet nuclei can reach the alveoli within the lungs where Mtb replicates. Individuals with Mtb infection can exhibit a wide range of clinical features that challenge current diagnostic approaches including acute active pulmonary infection with infective sputum, latent disease with risk of reactivation (especially in the immune-compromised host), sputum-negative and extrapulmonary Mtb infection and childhood tuberculosis (Wallis et al., 2010). In the majority of cases an infection with Mtb cannot be cleared and is contained by an effective immune response and the infection becomes latent and asymptomatic. About $10 \%$ of latently infected individuals progress to active reactivated disease during their lifetime. Thus individuals with latent Mtb infection act as infective foci of recurrent active disease and newly infect people in close contact. This large pool of undetected and untreated disease hampers eradication programs. 


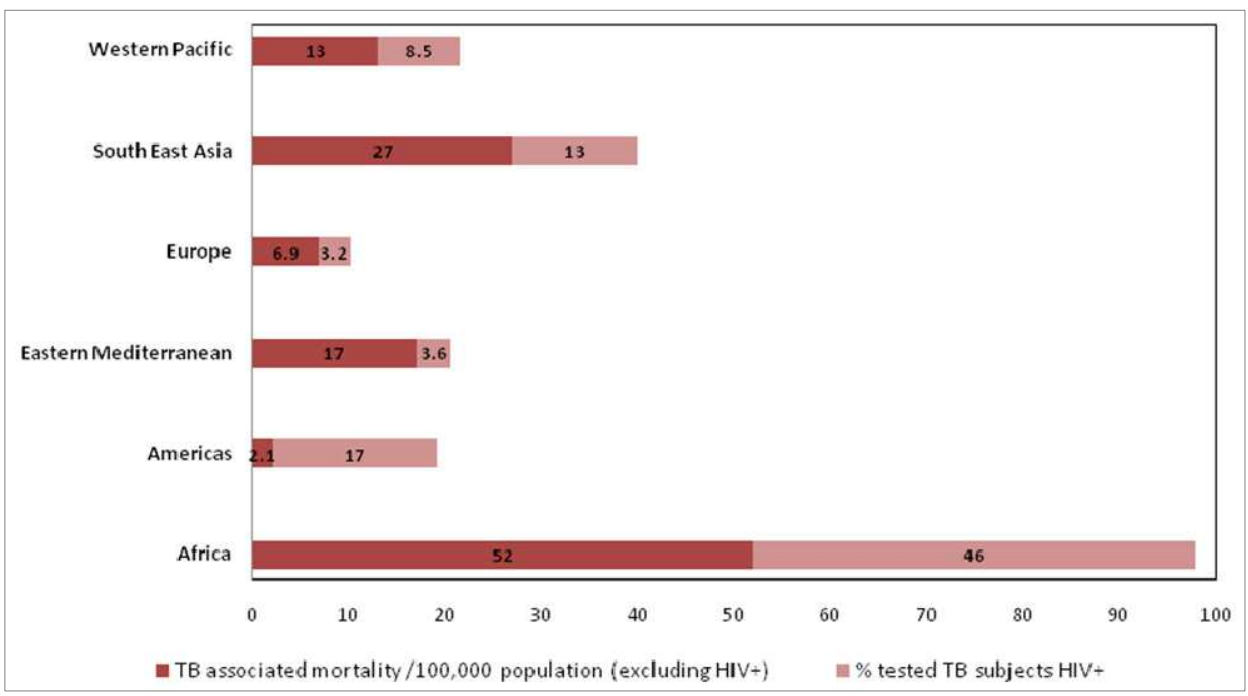

Fig. 1. Global Mtb burden of disease (2009). Data extracted from Global TB report 2010.

Global efforts to control Mtb center around improving both the rate of detection of cases and the treatment of infective subjects as reflected in the "The Stop TB strategy" published by the World Health Organisation (WHO) (WHO, 2006). The strategy aims to reverse the trend of rising incidence, halve the 1990 prevalence and mortality due to Mtb infection by 2015 and eliminate Mtb as a public health problem by 2050 (Maher et al., 2007). Successful implementation of the Stop TB strategy relies on accurate diagnostics for Mtb infection. Such an accurate diagnostic for Mtb infection should include the ability to identify adults and children with active infection, predict durable treatment success, and indicate and forecast reactivation of latent disease (Wallis et al., 2010). The ideal diagnostic tool would also need to remain trustworthy even in the setting of malnutrition and immunodeficiency and be performed within the primary care setting (Lucas et al., 2010). Given the enormity of the problem and the high prevalence in developing countries, the test(s) should also be simple and cheap. Despite major research efforts, a diagnostic assay or set of assays for Mtb infection that exhibit these properties is currently not available.

\section{Current diagnostic tools for active infection: Focus on pathogen detection and early immune activation}

Sputum-smear microscopy and chest radiography are still the primary tools to identify active Mtb infection in the typically resource-poor countries with a high-burden of Mtb disease (Figure 2). These tools can sometimes perform poorly and sputum is difficult to obtain from children. However, there are efforts to improve diagnostic assays available to developing countries including the development of assays that directly assay the pathogen. A summary of the main features of current diagnostics for active Mtb infection is given in Table 1. 
Diagnosis of active tuberculosis

\begin{tabular}{|c|c|c|c|c|c|}
\hline $\begin{array}{l}\text { Platform/ } \\
\text { Target }\end{array}$ & Assays & Description & $\begin{array}{l}\text { Disease/ } \\
\text { site }\end{array}$ & Disadvantages & Advantages \\
\hline $\begin{array}{l}\text { Sputum- } \\
\text { Smear } \\
\text { Microscopy }\end{array}$ & $\begin{array}{l}\text { Conven- } \\
\text { tional, FM, } \\
\text { LED }\end{array}$ & $\begin{array}{l}\text { Microscopic } \\
\text { observation } \\
\text { of stained } \\
\text { acid-fast } \\
\text { bacilli }\end{array}$ & Pulmonary & $\begin{array}{l}\text { Sputum difficult } \\
\text { to obtain from } \\
\text { children, } \\
\text { proportion } \\
\text { of individuals } \\
\text { smear negative, } \\
\text { reduced } \\
\text { sensitivity } \\
\text { in HIV+ } \\
\text { individuals }\end{array}$ & $\begin{array}{l}\text { FM } 10 \% \text { more } \\
\text { sensitive than } \\
\text { conventional } \\
\text { microscopy, LED FM } \\
\text { associated with low } \\
\text { cost, durability and } \\
\text { no need for } \\
\text { darkroom }\end{array}$ \\
\hline Culture & $\begin{array}{l}\text { Solid, } \\
\text { Liquid }\end{array}$ & $\begin{array}{l}\text { Monitor } \\
\text { changes in } \\
\text { media } \\
\text { resources to } \\
\text { detect } \\
\text { bacterial } \\
\text { growth }\end{array}$ & Pulmonary & $\begin{array}{l}\text { Long } \\
\text { turnaround } \\
\text { time due to } \\
\text { slow growth } \\
\text { of bacteria, } \\
\text { requires } \\
\text { biosafety } \\
\text { level } \\
3 \text { facilities }\end{array}$ & $\begin{array}{l}\text { Liquid culture more } \\
\text { sensitive than solid } \\
\text { cultures and higher } \\
\text { turnover rate }\end{array}$ \\
\hline
\end{tabular}

\begin{tabular}{|c|c|c|c|c|c|}
\hline Biochemical & $\begin{array}{l}\text { Adenosine } \\
\text { deaminase }\end{array}$ & $\begin{array}{l}\text { Detection of } \\
\text { host enzyme } \\
\text { released in } \\
\text { response to } \\
\text { intracellular } \\
\text { pathogen }\end{array}$ & $\begin{array}{l}\text { Pleuritis, } \\
\text { pericarditis, } \\
\text { peritonitis }\end{array}$ & & $\begin{array}{l}\text { ADA levels in } \\
\text { pleural, pericardial } \\
\text { and ascitic } \\
\text { fluid has high } \\
\text { specificity and } \\
\text { sensitivity for } \\
\text { extrapulmonary } \\
\text { Mtb infection }\end{array}$ \\
\hline \multirow[t]{2}{*}{ Pathogen } & $\begin{array}{l}\text { Nucleic } \\
\text { acid } \\
\text { amplifi- } \\
\text { cation tests }\end{array}$ & $\begin{array}{l}\text { Detection of } \\
\text { Mtb genetic } \\
\text { material }\end{array}$ & $\begin{array}{l}\text { Pulmonary } \\
\text { and extra- } \\
\text { pulmonary }\end{array}$ & $\begin{array}{l}\text { Variable } \\
\text { sensitivity } \\
\text { especially } \\
\text { in smear -ve } \\
\text { and } \\
\text { extrapulmonary } \\
\text { disease }\end{array}$ & $\begin{array}{l}\text { High specificity and } \\
\text { positive predictive } \\
\text { value }\end{array}$ \\
\hline & $\begin{array}{l}\text { Mtb } \\
\text { antigens }\end{array}$ & $\begin{array}{l}\text { Detection of } \\
\text { circulating } \\
\text { Mtb antigens }\end{array}$ & $\begin{array}{l}\text { Pulmonary } \\
\text { and extra- } \\
\text { pulmonary }\end{array}$ & $\begin{array}{l}\text { Variable } \\
\text { sensitivity }\end{array}$ & $\begin{array}{l}\text { Quick and relatively } \\
\text { easy assay to } \\
\text { perform }\end{array}$ \\
\hline Serological & & $\begin{array}{l}\text { Detection } \\
\text { of host } \\
\text { humoral } \\
\text { response to } \\
\text { pathogen }\end{array}$ & $\begin{array}{l}\text { Active and } \\
\text { latent Mtb } \\
\text { disease }\end{array}$ & $\begin{array}{l}\text { Inconsistent } \\
\text { estimates of } \\
\text { sensitivity and } \\
\text { specificity }\end{array}$ & $\begin{array}{l}\text { Fast turnaround and } \\
\text { can be used for } \\
\text { children }\end{array}$ \\
\hline
\end{tabular}


Diagnosis of active tuberculosis

\begin{tabular}{|c|c|c|c|c|}
\hline $\begin{array}{l}\text { Platform/ } \\
\text { Target }\end{array}$ & Assays & $\begin{array}{c}\text { Description } \begin{array}{l}\text { Disease/ } \\
\text { site }\end{array}\end{array}$ & Disadvantages & Advantages \\
\hline \multirow[t]{2}{*}{$\begin{array}{l}\text { Immuno- } \\
\text { logical } \\
\text { markers }\end{array}$} & TST & $\begin{array}{l}\text { Measurement } \\
\text { of induration } \\
\text { as a result of } \\
\text { exposure to } \\
\text { intradermal } \\
\text { tuberculin }\end{array}$ & $\begin{array}{l}\text { BCG vaccinated } \\
\text { subjects more } \\
\text { likely to be } \\
\text { positive }\end{array}$ & $\begin{array}{l}\text { Quick and relatively } \\
\text { easy assay to } \\
\text { perform }\end{array}$ \\
\hline & IGRAs & $\begin{array}{l}\text { Measurement } \\
\text { of interferon } \\
\text { gamma } \\
\text { released } \\
\text { from } \\
\text { lymphocytes } \\
\text { when } \\
\text { stimulated } \\
\text { with Mtb } \\
\text { antigens }\end{array}$ & $\begin{array}{l}\text { Cannot } \\
\text { distinguish } \\
\text { between latent } \\
\text { and active Mtb } \\
\text { infection, } \\
\text { sensitivity may } \\
\text { be lower in } \\
\text { HIV+ subjects }\end{array}$ & $\begin{array}{l}\text { High specificity and } \\
\text { unaffected by } \\
\text { previous BCG } \\
\text { vaccination }\end{array}$ \\
\hline
\end{tabular}

References include (Wallis et al., 2010), (Daley et al., 2007; Greco et al., 2003; Mase et al., 2007), (Dinnes et al., 2007), (Jiang et al., 2007), (Flores et al., 2005; Greco et al., 2006; Ling et al., 2008), (Pai et al., 2003; Pai et al., 2004), (Sarmiento et al., 2003; Steingart et al., 2007a; Steingart et al., 2007b; Steingart et al., 2006a; Steingart et al., 2006b), (Pai et al., 2010), (Pai et al., 2008), (Goto et al., 2003; Kalantri et al., 2005), (Liang et al., 2008; Riquelme et al., 2006; Tuon et al., 2006).

Table 1. Review of current diagnostics for Mtb infection.

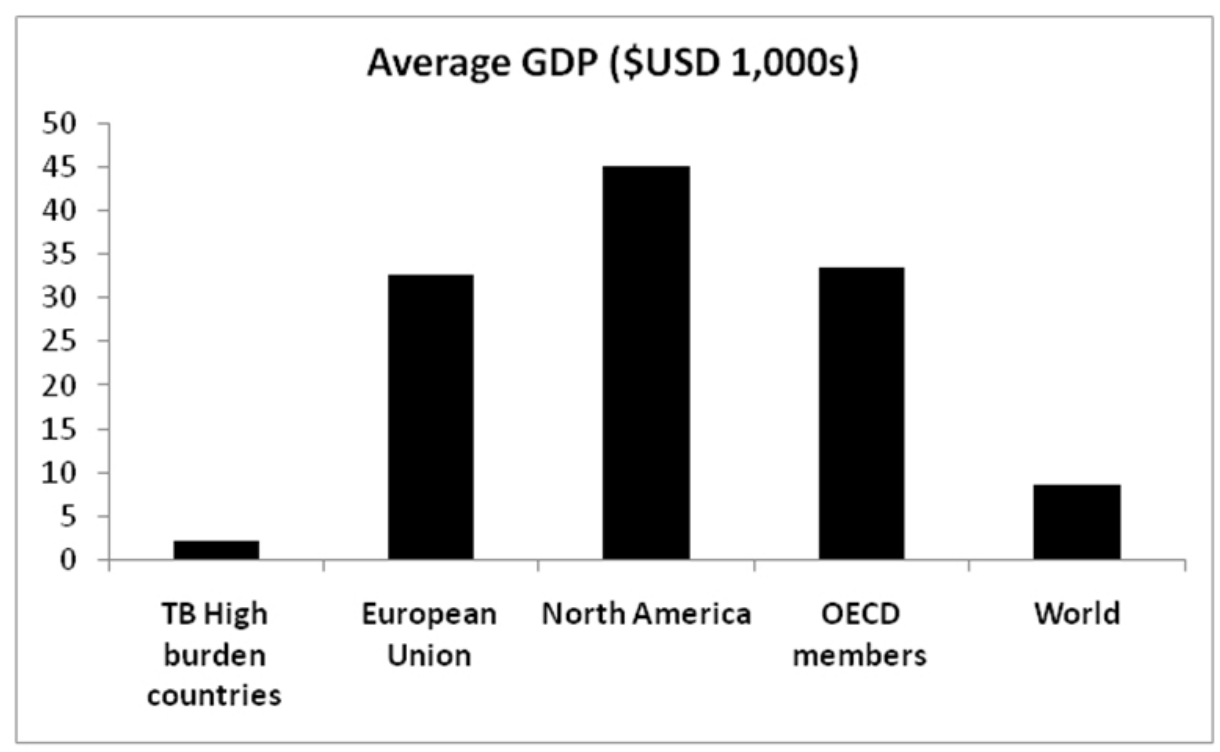

Fig. 2. Average gross national product (\$USD) for 2009 for selected nations. Data extracted from Global TB report 2010 and The World Bank. 


\subsection{Pathogen detection}

\subsubsection{Microscopy}

Ziehl-Neelsen sputum-smear microscopy with a conventional light microscope is commonly used to identify acid-fast bacilli in sputum to diagnose active Mtb infection in low and middle-income countries with a high prevalence of Mtb disease. This assay identifies the most infectious patients and is a quick and relatively easy procedure that is widely applicable but also requires multiple sample collections over several days (usually 3 days) and is dependent on the quality and bacterial load of the sputum specimen. The use of acidfast fluorochrome dyes with fluorescence-based microscopy (FM) is a standard assay performed in high-income countries to detect Mtb. FM has greater sensitivity than conventional microscopy and can be performed in less time but the need for a dark room and considerable outlay costs make it less amenable for resource poor countries. The recent development of light-emitting diode (LED) fluorescence microscopy may overcome some of the difficulties associated with the widespread implementation of FM (Cuevas et al., 2011). In the setting of laboratories, which contribute to a well-functioning external quality assurance system, revised WHO guidelines for the diagnosis of pulmonary Mtb infection include the reduction in the minimum number of samples that need to be tested (from three to two), given that the inclusion of a third sample only increases sensitivity by $2-5 \%$ (Pai et al., 2008). This move could significantly reduce the local collection and testing costs and increase the successful collection rate of samples. Furthermore, the addition of simple sputum processing methods (including the use of household bleach and centrifugation) can improve sensitivity of sputum-smear microscopy. However, it is important to remember that a positive acid-fast staining result may represent the presence of non-tuberculosis mycobacteria.

\subsubsection{Microbiological culture}

Clinical specimens suspected of containing Mtb can be inoculated onto a culture media. Culture of $\mathrm{Mtb}$ on solid media (typically egg or agar-based) is more sensitive than sputumsmear microscopy for the diagnosis of active Mtb infection and can differentiate between species of mycobacteria but can take weeks to perform due to the slow growth of Mtb and related organisms. The sensitivity of cultures is generally between $80-85 \%$ with a specificity of about $98 \%$ (Prevention, 2000). The use of liquid cultures can reduce bacterial growth times (1-3 weeks compared to 3-8 weeks), can be automated and have sensitivity and specificity levels close to $100 \%$. However, the use of such cultures requires a biosafety level 3 environment and equipment and consumables which are relatively expensive, although cheaper products may become available for developing countries (WHO, 2006).

\subsubsection{Direct detection of pathogen nucleic acid}

The genus Mycobacterium consists of over 80 species and many appear similar on acid-fast staining; a limitation of sputum-smear microscopy. Although cultures offer some differentiation between species, these assays have a slow turnaround time that results in a delay in diagnosing Mtb infection. Amplification and detection of Mtb DNA directly from specimens can be an efficient and sensitive method to detect Mtb infection and may also allow for the detection of mutations in the Mtb genome associated with drug resistance. 
In theory, nucleic acid amplification tests (NAATs) could identify a single mycobacterium at the species level but first generation NAATs were not sufficiently reliable to replace conventional diagnostic methods for Mtb infection (Greco et al., 2006). False negative results using these assays may have been due to sampling issues (given small volumes needed for test) and possible presence in specimens of inhibitors of the amplification process. False positive results may have been due to contaminations given the inherent increased risk in these assays due to the common amplification step. Subsequent improvements using internal controls (to identify assay inhibitors) and automated systems using a single sealed tube (reduce contamination) have improved the sensitivity and specificity of these assays.

A review of several commercial NAATs showed a mean sensitivity of $96 \%$ and specificity of $85 \%$ for smear-positive cases and $66 \%$ sensitivity and $98 \%$ specificity for smear negative cases (Greco et al., 2006). Importantly, these NAATs could exclude Mtb in patients with smear positive microscopy in which environmental mycobacteria is suspected.

The fully automated Xpert Mtb device, which was developed by a consortium that included both commercial and publicly funded organisations (Cepheid Inc.; Foundation for Innovative New Diagnostics) has been endorsed by WHO for use in Mtb endemic countries (http://www.who.int/mediacentre/news/releases/2010/tb_test_20101208/en/index.html).

The device does not require extensive staff training and produces results from the assay on the same day (WHO, 2006). The first assessment of the new system suggests it is highly sensitive for both smear positive and smear negative samples (Wallis et al., 2010) and the negotiation that the price per test would be reduced by $75 \%$ in countries most effected by TB should make this broadly accessible as an effective point-of-care diagnostic tool.

\subsubsection{Mtb antigen detection}

Assays that directly assess the presence of circulating Mtb antigens in serum, sputum, urine, cerebrospinal and pleural fluid to diagnose active Mtb disease are widely used. However, a recent review of Mtb antigen assays showed that of 47 studies examining pulmonary Mtb, the sensitivity of the assays varied from $2-100 \%$ and specificity varied from $33-100 \%$ (Flores et al., 2011). Furthermore, 21 studies examining extrapulmonary Mtb using Mtb antigen assays showed sensitivity levels varying from $0-100 \%$ and specificity from $62-100 \%$. Most assays utilised the Mtb cell wall protein lipoarabinomannan (LAM) but some assays used multiple Mtb antigens. Interestingly, the detection of LAM in urine samples tended to have higher sensitivity in HIV+ patients than in HIV negative patients for Mtb diagnosis. However, much research is needed to improve the performance of these assays given the relative ease of translation into the primary care setting and is likely to be centred on identifying Mtb antigens that are abundantly expressed, specific to Mtb and resistant to the host's immune response.

\subsection{Early immune activation markers}

\subsubsection{Biochemical}

The diagnosis of Mtb meningitis is difficult due to the low sensitivity of identifying acid-fast bacilli in cerebrospinal fluid with microscopy and the length of time required for the culture 
growth of Mtb. As an alternative, the enzyme adenosine deaminase (ADA), which is widely distributed in pleural, meningeal and pericardial fluids, is used in the diagnosis of Mtb pleuritis, pericarditis and peritonitis. The host enzyme is released from lymphocytes in response to infection with intracellular pathogens (Pai et al., 2010). The biochemical assay used to quantity ADA is quick and non-invasive. A recent systematic review of 10 studies involving 1364 participants showed the ADA assay exhibited a mean sensitivity of $79 \%$ and mean specificity of $91 \%$ for Mtb meningitis (Xu et al., 2010). However, the study stresses that a negative ADA assay does not rule out Mtb meningitis and should not be used alone to make clinical decisions regarding treatment of a patient.

\subsubsection{The potential role of early immune markers in the diagnosis of acute Mtb infection}

Initial pathogen recognition of Mtb by macrophages occurs via toll-like receptors (TLRs), resulting in the induction of transcription of pro-inflammatory cytokine genes essential to direct the subsequent immune response (Berrington and Hawn, 2007). Mtb ligands for TLRs include CpG DNA, triggering the intracellular TLR-9, and LAM and mannosylated phosphotidylinositol acting mainly via TLR-2 (in association with TLR-1, -4 and -6) (Constantoulakis et al., 2010). Once uptake into macrophages has occurred, Mtb has unique mechanisms to survive within the phagocytes, for example by blocking biogenesis of the phagolysosome. A recent study assessed mRNA expression of a combination of these innate markers, namely TLR-2, Coronin 1, a protein which arrests the maturation of the phagolysosome within macrophages, and Sp110, a protein complex important for monocyte differentiation and apoptosis in Mtb infection. This study revealed significantly elevated levels of mRNA of all three proteins in subjects with active and latent Mtb disease as compared to healthy uninfected subjects (Chen et al., 2010). However, larger case-controlled studies are needed to confirm these findings and evaluate these factors as future diagnostic biomarkers for Mtb infection.

Another potential immune marker of Mtb infection is Neopterin. Neopterin is secreted when macrophages are activated through exposure to interferon gamma (IFN- $\gamma$ ) and its concentration in serum is increased in the early stages of infection whilst its levels decrease following successful treatment and increasing again upon relapse. As such it can be used as a non-specific pro-inflammatory marker for $\mathrm{Mtb}$ as its detection is also associated with other chronic infections that commonly coexist with Mtb, such as HIV, malaria, Hepatitis B and C (Fuchs et al., 1984; Immanuel et al., 2001; Turgut et al., 2006; Wallis et al., 1996).

Other examples of innate markers that have been shown to be increased in Mtb infection are the soluble intercellular adhesion molecules (Walzl et al., 2008), the acute phase reactant proteins (Djoba Siawaya et al., 2008), soluble urokinase plasminogen activator receptor (Eugen-Olsen et al., 2002), CXCL10/IP10 and Pentraxin 3 (Azzurri et al., 2005), and procalcitonin (Baylan et al., 2006; Kandemir et al., 2003; Nyamande and Lalloo, 2006; Prat et al., 2006; Schleicher et al., 2005).

Recently, an elegant study by Anne O'Garra and colleagues identified a 393-whole blood transcript signature for active $\mathrm{Mtb}$, which correlated with clinical and radiological disease as well as treatment response. One of the surprising findings of this study was the dominant induction of genes of the IFN- $\gamma$ and type I interferon pathways in neutrophils 
(Berry et al., 2010). This indicates the potential power of using innate responses as surrogate markers of $\mathrm{Mtb}$ infection and the strength of using a combination of markers for multiplex analyses.

Despite the lack of specificity to Mtb disease associated with these innate immune markers, the measurement of these surrogate markers is technically straightforward and the assays are often readily available. It may be that by combining multiple markers distinct pathogen associated patterns will be described. Certainly the development of multiplexed assays for soluble proteins and the definition of gene expression profiles for Mtb disease by gene expression analysis (Jacobsen et al., 2007; Maertzdorf et al., 2010), such as those offered for the Luminex platform (Luminex Corp.), will continue to make this process more feasible.

\section{Current diagnostic tools for latent infection: Focus on immune memory and cytokine based diagnostics}

Overall, human $\mathrm{T}$ cell responses to Mtb involve CD4+, CD8+ and gamma-delta T cells. Akin to chronic viral infections, a broad $\mathrm{T}$ cell repertoire able to recognise many different types of bacterial epitopes (proteins as well as lipids) enhances the efficiency of the immune response against Mtb (Boom et al., 2003). The balance between different T helper subsets, especially Th1, T (Fox P3+) regulatory cells and Th17 helper cells may also be a key factor (Korn et al., 2007; Liang et al., 2006; Marin et al., 2010; Torrado and Cooper, 2010) and could potentially be explored for diagnostic purposes.

For some time, assays assessing the presence of Mtb specific memory CD8 and CD4 T cells have been used to identify those who previously have been infected with Mtb. Mtb-specific T cells are detectable within $2-3$ weeks of acute infection in the peripheral blood and mark the end of the phase of rapid bacterial replication and bacterial containment. Interestingly, studies in mice suggest a late adaptive $\mathrm{T}$ cell response, which is linked to a delay in activation of $\mathrm{T}$ helper cells (Wolf et al., 2008). The measurement of Mtb specific T cells is therefore diagnostically insensitive in acute infection. This apparent problem may be overcome by the detection of Mtb-specific T cells directly at the site of infection, such as in fluid from broncho-alveolar lavage and cerebrospinal fluid, during early stages of disease in selected cohorts (Jafari et al., 2009; Thomas et al., 2008). On the other hand, the long-term maintenance of memory $\mathrm{T}$ cell responses to pathogens in peripheral blood (Semmo et al., 2006) make the measurements of Mtb specific T cells useful as a diagnostic cross-sectional assay to test for prior exposure to Mtb.

\subsection{Tuberculin skin test and Interferon-y release asssays (IGRA)}

One of the current well established diagnostic approaches, which is based on a $\mathrm{T}$ cell mediated delayed hypersensitivity reaction, is the tuberculin skin test (TST). The TST is generally performed by an intradermal injection of 5 tuberculin units using purified protein derivative (PPD) following the Mantoux method. The transverse diameter of the skin induration occuring after 48-72 hours is typically measured. Therefore at least two clinic visits are required for a valid test which may prove a problem. In our recent study of Western Australian refugee children, the TST was initiated in 341 children; however reading 
was not possible in $37(11 \%)$ children due to non-attendance at clinic appointments or absence of the child at scheduled home visits (Lucas et al., 2010). The interpretation of results and determination of cut-offs also varies and is infuenced by age, previous BCG vaccination and Mtb infection risk. In addition, this method is now recognised to have other limitations, such as poor specificity due to cross reactivity with both non-tuberculous mycobacteria and BCG (National Health Service, 2005) (Table 1).

More recently, measurement of IFN- $\gamma$-producing memory T cells specific for Mtb has been introduced into the clinical practice of many countries. Two blood-based IFN- $\gamma$ release assays (IGRAs) are available for diagnostic use, the Quantiferon-TB gold in-tube (QFT-GIT; Cellestis, Carnegie, Australia) and the T-SPOT.TB (Oxford Immunotech,Oxford, UK). Both assays have high specificity for adult Mtb infection including in BCG-vaccinated populations (Lucas et al., 2010). Both assays measure T cell IFN-ץ production in response to antigens encoded by the RD1 gene which is present in all strains of Mtb but is not present in the Mycobacterium bovis genome from which BCG is derived. This eliminates BCG crossreactivity, however cross-reactivity to a limited number of non-Mtb mycobacteria ( $M$. kansasii, M. szulgai, M. marinum) remains. T-SPOT.TB is an enzyme-linked immunospot (ELISpot) assay that measures the response to two antigens, early-secreted antigenic target 6 (ESAT-6) and culture filtrate protein 10 (CFP-10). The QFT-GIT assay is a whole blood IGRA assay that includes an additional Mtb-specific antigen (TB7.7). In the few head-to head comparisons of the latest generation tests, T-SPOT.TB and QFT-GIT both perform satisfactorily. Some studies however suggest that the use of the T-SPOT.TB assay may be the preferred option in subjects with primary and secondary (HIV, iatrogenic) immunodeficiencies (Lalvani, 2007; Pai et al., 2008b).

To date, there has been limited focus on high incidence paediatric populations, which are at greater risk of reactivation and extrapulmonary manifestations of Mtb, including TB meningitis. We recently published a prospective comparative study of IGRAs and TST for the diagnosis of LTBI in 524 refugee children from countries with a high prevalence of MTb that resettled to Australia (Lucas et al., 2010). This study included 182 children $<5$ years of age. In our study, the T-SPOT.TB and QFT-GIT had similar rates of positivity $(8 \%$ and $10 \%$, respectively) and showed good concordance when both tests gave definitive results (kappa $=0.78 ; \mathrm{p}<0.0001)$. Surprisingly, both IGRAs had significant failure rates: $15 \%$ of QFT-GIT gave indeterminate results due to failed mitogen response and $14 \%$ of TSPOT.TB results were inconclusive because of insufficient mononuclear leukocyte yields. Failure of the QFT-GIT mitogen response was associated with African ethnicity and comorbid infections, particularly with helminths. Overall, the TST results showed low concordance (about 50\%) with both IGRAs. This study highlights the influence of age, ethnicity and clinical status on IGRA results and the limitations of using these T cell based tests in refugee children.

In general, IGRAs are likely to be too complex and expensive for point-of-care testing in the Developing World, but their use in developed countries where the Mtb burden is much smaller, is currently justified. In addition, they have a role in the identification of subjects with latent $\mathrm{Mtb}$ prior to immunosuppressive therapy, including treatment with novel biologic drugs such as TNF- $\alpha$ antagonists (Bellofiore et al., 2009). 


\subsection{Assessment of the role of other cytokines in Mtb infection}

As the cooperation between macrophages and $\mathrm{T}$ lymphocytes is critical for acute and longterm control of Mtb, cytokines produced during their interaction, such as IL-1, IL-2, IFNTNF- $\alpha$, IL-12 and IL-23 are thought to play a critical role, all of which have potential to be used as surrogate markers of anti-Mtb immunity (Doherty et al., 2009). In addition, there is increasing evidence that during acute $\mathrm{Mtb}$ infection many of these pro-inflammatory cytokines are counteracted by induction of immune suppressive regulators (such as IL-10, TGF- $\beta$ RII, IL1-R and IDO) in addition to upregulation of intracellular molecules, e.g. IRAK$\mathrm{M}$ and suppressor of cytokine signalling (SOCS) (Almeida et al., 2009). Mtb-activated CD4+ $\mathrm{T}$ cells also release TNF- $\alpha$ which can trigger cell lysis in infected macrophages and may kill intracellular Mtb (Canaday et al., 2001) and Mtb specific TNF- $\alpha$ secreting CD4+ T cells have been shown to be more frequent during active than latent disease (Harari et al., 2011). In addition, IL- 18 from macrophages and DCs has recently been explored for its protective immunity against tuberculosis (Schneider et al., 2010). Newer diagnostic approaches that allow the measurement of mulitple cytokine simultaneously may aid in the diagnosis of latent infection, but also are promising tools for the identification of acute infection/reactivation/infection of Mtb.

\subsection{Antibody responses to Mtb}

Serological blood tests detect the host's humoral response (antibodies) to a pathogen that can remain circulating in the blood for several years. However, as with any pathogen specific immune response (antibody or T cell) this response develops after initial infection, and therefore its use at early infection timepoints is limited. Overall, these tests can be quick and inexpensive to perform using either ELISA or immunochromatographic formats. In the case of Mtb infection, serological assays would also be more practical for children, for whom sputum samples are difficult to obtain.

It is estimated that more than a million Mtb serological tests are performed each year, predominantly in high disease burden countries (Steingart et al., 2011). However, many of these assays vary in the antigens used, source and type of antigen and the class of immunoglobulin investigated. First generation antibody assays used crude mixtures of Mtb that tended to give low specificity results; most likely due to shared antigens between mycobacteria species. A review to assess the efficacy of "in-house" serological assays showed that assays with a combination of antigens gave higher sensitivity and specificity than earlier assays (Steingart et al., 2009). Furthermore, assays detecting IgG and IgA anti$\mathrm{Mtb}$ antibodies gave higher sensitivity values for the detection of pulmonary Mtb than IgMbased assays. IgM-based assays may be better suited to the detection of acute Mtb infection as IgM is typically expressed early in the infection but then dissipates over time.

A recent systematic review commissioned by the WHO clearly showed that commercial serological assays for active Mtb infection exhibited substantial variation in sensitivity and specificity for pulmonary Mtb infection ((Steingart et al., 2011); Table 1). The review was based on 67 studies with 5,147 participants including $48 \%$ from low-middle income countries. Accordingly, on the $20^{\text {th }}$ July 2011, WHO released a press statement warning against the use of serological tests for the diagnosis of active Mtb infection, stating that the 
currently available commercial serological tests exhibit low specificity and sensitivity leading to misdiagnosis, mistreatment and potential harm to public health (http://www.who.int/mediacentre/news/releases/2011/tb_20110720n/index.html).

The role of a protective antibody response in Mtb has been less investigated. Approximately $90 \%$ of patients produce antibodies to Mtb proteins with antibody profiles showing great inter-individual variation. So far, a clear correlation between antibody profiles and disease status has not been clearly established, making its use for routine diagnostics problematic (Lyashchenko et al., 1998; Wu et al., 2010). Recently, a major contribution to the field has been published by Kunnath-Velayudhan and colleagues (Kunnath-Velayudhan et al., 2010). They screened 500 sera from suspected Mtb infected subjects against the entire Mtb proteome using high-throughput microarray technology and identified signatures of antibody responses in subjects with active $\mathrm{Mtb}$, with some variation across subjects, thus providing novel insights into the biology of the humoral response against Mtb and providing further steps to develop effective humoral immunodiagnostics.

\section{Diagnosis of reactivation disease or low level pathogen detection}

Upon inhalation of Mtb, mycobacteria are phagocytosed by alveolar macrophages that recruit mononuclear cells to the site of infection. This leads to the characteristic granuloma formation consisting of macrophages, monocytes and neutrophils. At later stages, the granuloma becomes more organised and infiltrated by lymphocytes (Russell et al., 2010). For the majority of cases $\mathrm{Mtb}$ is contained by the immune system. How the transition between the detection and control of acute infection to the establishment of latent Mtb infection is mediated, remains unknown. A critical factor, however, is the pathogen's ability to evade its complete elimination by the immune system. Studies have shown that even asymptomatic infected hosts harbour virulent bacteria in their tuberculous granulomas (Bouley et al., 2001; Tufariello et al., 2003). It is even possible that the granulomas paradoxically offer a niche for long-term survival of the bacteria. The barrier of activated macrophages and giant multinucleated cells that surround Mtb infected cells within granulomas are relatively impermeable to T cell infiltration although $\mathrm{T}$ cells remain closely associated at the site of infection (Tufariello et al., 2003). Thus paradoxically the combined efforts of the innate and adaptive immune response often contain and control the infection but fail to eliminate it. In fact the presence of $\mathrm{Mtb}$ antigens released into the host are thought to maintain the presence of an Mtb specific effector-memory population, which is absent in cases who have successfully eliminated the pathogen and only show evidence of a Mtb-specific central memory T cells (Millington et al., 2010). Ongoing adaptive immunity is essential in preventing reactivation of infection at a later stage (Boom et al., 2003). Reactivation disease occurs when latent bacteria from old, scarred granulomatous lesions are reactivated into an active, virulent state. A increased risk of reactivation arises when the host's immune system is compromised, which may be secondarily due to immune suppressive drugs, especially those that modify Mtb-specific immunity such as TNF- $\alpha$ antagonists, due to cancer, malnutrition or chronic viral infections, such as HIV. HIV+ individuals with advanced disease and low CD4+ T cell count face an approximate $10 \%$ risk per year of Mtb reactivation and co-infection of Mtb with HIV is now well documented (Shen et al., 2004). In the developing world therefore, Mtb has become one of the leading causes of death (Tufariello et al., 2003). This also highlights the problem that those with the greatest risk of reactivation are often cared for by those that are most vulnerable for Mtb infection and re- 
infection. Not surprisingly, this vicious cycle of reactivation/infection in developing countries has led to a flourishing Mtb spread and extensive resistance to most anti-Mtb drugs.

To-date no reliable routine diagnostics that allow pathogen recognition at low levels or immune markers that predict reactivation are available. In general, the principles underlying the diagnosis of reactivation disease will be similar to those used for the detection of early acute infection; namely pathogen based assays and assays which rely on immune markers associated with the innate immune system (see above). In addition, there are reports which suggest that a change in T cell based immunity against Mtb exists in acute and latent infection.

Casey et al., for example, expands the current technology of the T-SPOT.TB assay by measuring IFN- $\gamma$ and IL-2 responses by Mtb specific T cells after stimulation with ESAT 6 and CFP 10 antigens, thus aiming to test $\mathrm{T}$ cells for polyfunctionality in active, treated and latent Mtb (Casey et al., 2010). The authors use a dual fluorescent ELISpot to measure two cytokines simultaneously, which could be adapted to routine -albeit expensive- clinical practice. They demonstrated that active untreated Mtb, compared to latent Mtb infection, was dominated by IFN- $\gamma$-only producing effector T cells. In addition, sequential testing of successfully treated patients revealed a shift from IFN- $\gamma$ only producing $\mathrm{T}$ cells to a higher number of effector-memory cells secreting IL-2 and IFN- $\gamma$ which confirms previous data, using a flowcytometric approach, by Caccamo et al (Caccamo et al., 2010).

\section{Use of genetic studies to identify novel genes involved in Mtb pathogenesis}

Recent technological advances has allowed the large-scale sampling of the human genome in a cost-effective manner and now allows researchers to examine, without a priori knowledge, genetic variations that may influence Mtb infection outcome. Furthermore, the deposit of whole genome sequences from individuals from different ethnic backgrounds into public databases allows a more comprehensive view of human genetic variation that better reflects the individuals at most risk of Mtb infection.

Genome-wide linkage studies to identify the transfer of chromosomal regions containing susceptibility genes, typically using families of affected individuals, have been performed on Mtb (reviewed in (Moller et al., 2009)). However, of the studies to date, none of the linkage peaks reach genome-wide significance. The majority of these studies targeted different populations and not surprisingly there is no obvious overlap between highlighted chromosome regions for each study.

The only reported genome-wide association study to date for Mtb involves the African TB Genetics consortium and the Wellcome Trust Case Control Consortium (Thye et al., 2010). In this study, individuals with tuberculosis and unaffected controls from the West African nations Ghana and The Gambia were genotyped for single nucleotide polymorphisms (SNPs) covering the entire genome. The initial study identified 17 loci associated with disease with a $\mathrm{p}^{<10^{-5}}$. However, subsequent replication studies found that the SNP rs4331426 had the highest association signal (OR 1.19; total number of individuals 11,425). Interestingly, this SNP is located within a gene-poor region of chromosome 18 (18q11.2) but does contain the gene GATA6, which encodes a transcription factor known to regulate arachidonate 15-lipoxygenase (ALOX15); a molecule involved in regulating the release of 
cytokines in lung epithelia cells ((Liu et al., 2009); reviewed in (Vannberg et al., 2011)). Although the role of this gene in Mtb susceptibility has not been clarified, it certainly remains a gene of interest.

But it is important to remember that Mtb is also a variable pathogen and it is likely that variation in the genetics of the host and pathogen are likely to be relevant in determining infection outcome.

\section{Conclusion}

Microbiological detections systems are likely to remain the gold standard for detection and identification of extracellular pathogens aided by the increasing complementary usage of PCR to shorten the time and improve the accuracy of identification. Future developments may also include screening of other less invasive sample types including volatile samples from the breath, for the presence of characteristic pathogen associated molecules or metabolic bi-products (Phillips et al., 2007). Sensitive physical detection technologies like those based on mass spectrophotometry (Metzger et al., 2010) may also make their way into larger clinical laboratories to assist in sample analysis.

Newly described cytokine networks such as those associated with inflammasome complexes (IL-1 $\beta$, IL-18, IL-33) (Church et al., 2008), the IL-23/IL-17 inflammatory pathway (Kikly et al., 2006) are being studied at a basic research level and are likely to contribute additional insights into anti-pathogen immunity. The continued development of better assays for established biomarkers (e.g. monokine assay; Chakera et al., 2011) to improve sensitivity and specificity and the speed in which results are obtained or give additional insights into the immune responses to the pathogen will be central to these advances.

The complexities that underlie effective pathogen specific immunity is still incompletely understood and will continue to be informed by data generated using molecular approaches that measure changes in pathways that influence the response to infection. Advances in the CHIP technology (Weinmann et al., 2002), which involves the selection of specific DNA binding proteins by antibodies, will add additional dimension to the data being obtained and show which genetic levers are being pulled during a response to a given pathogen. Furthermore, this technology is complemented by Next-generation sequencing that will allow the detection of low frequency viral and host variants as well as transcripts. It is hoped that insights generated by such approaches, along with further iterations of these technologies will result in more sophisticated approaches and tools to be developed, affordable to the countries burdened with the highest levels of Mtb.

\section{References}

Almeida, A. S., P. M. Lago, et al. (2009). "Tuberculosis is associated with a down-modulatory lung immune response that impairs Th1-type immunity." J Immunol 183(1): 718-31.

Azzurri, A., O. Y. Sow, et al. (2005). "IFN-gamma-inducible protein 10 and pentraxin 3 plasma levels are tools for monitoring inflammation and disease activity in Mycobacterium tuberculosis infection." Microbes Infect 7(1): 1-8.

Baylan, O., A. Balkan, et al. (2006). "The predictive value of serum procalcitonin levels in adult patients with active pulmonary tuberculosis." Jpn J Infect Dis 59(3): 164-7. 
Bellofiore, B., A. Matarese, et al. (2009). "Prevention of tuberculosis in patients taking tumor necrosis factor-alpha blockers." J Rheumatol Suppl 83: 76-7.

Berrington, W. R. and T. R. Hawn (2007). "Mycobacterium tuberculosis, macrophages, and the innate immune response: does common variation matter?" Immunol Rev 219: 167-86.

Berry, M. P., C. M. Graham, et al. (2010). "An interferon-inducible neutrophil-driven blood transcriptional signature in human tuberculosis." Nature 466(7309): 973-7.

Boom, W. H., D. H. Canaday, et al. (2003). "Human immunity to M. tuberculosis: T cell subsets and antigen processing." Tuberculosis (Edinb) 83(1-3): 98-106.

Bouley, D. M., N. Ghori, et al. (2001). "Dynamic nature of host-pathogen interactions in Mycobacterium marinum granulomas." Infect Immun 69(12): 7820-31.

Caccamo, N., G. Guggino, et al. (2010). "Multifunctional CD4(+) T cells correlate with active Mycobacterium tuberculosis infection." Eur J Immunol 40(8): 2211-20.

Canaday, D. H., R. J. Wilkinson, et al. (2001). "CD4(+) and CD8(+) T cells kill intracellular Mycobacterium tuberculosis by a perforin and Fas/Fas ligand-independent mechanism." J Immunol 167(5): 2734-42.

Casey, R., D. Blumenkrantz, et al. (2010). "Enumeration of functional T-cell subsets by fluorescence-immunospot defines signatures of pathogen burden in tuberculosis." PLoS One 5(12): e15619.

Chakera A, Bennett SC, et al. (2011). "A whole blood monokine-based reporter assay provides a sensitive and robust measurement of the antigen-specific $\mathrm{T}$ cell response." J Transl Med. 9(1):143.

Chen, Y. C., C. C. Hsiao, et al. (2010). "Toll-like receptor 2 gene polymorphisms, pulmonary tuberculosis, and natural killer cell counts." BMC Med Genet 11: 17.

Church, L. D., G. P. Cook, et al. (2008). "Primer: inflammasomes and interleukin 1beta in inflammatory disorders." Nat Clin Pract Rheumatol 4(1): 34-42.

Constantoulakis, P., E. Filiou, et al. (2010). "In vivo expression of innate immunity markers in patients with Mycobacterium tuberculosis infection." BMC Infect Dis 10: 243.

Corbett, E. L., B. Marston, et al. (2006). "Tuberculosis in sub-Saharan Africa: opportunities, challenges, and change in the era of antiretroviral treatment." Lancet 367(9514): 92637.

Cuevas, L. E., N. Al-Sonboli, et al. (2011). "LED fluorescence microscopy for the diagnosis of pulmonary tuberculosis: a multi-country cross-sectional evaluation." PLoS Med 8(7): e1001057.

Daley, P., S. Thomas, et al. (2007). "Nucleic acid amplification tests for the diagnosis of tuberculous lymphadenitis: a systematic review." Int J Tuberc Lung Dis 11(11): 1166-76.

Dinnes, J., J. Deeks, et al. (2007). "A systematic review of rapid diagnostic tests for the detection of tuberculosis infection." Health Technol Assess 11(3): 1-196.

Djoba Siawaya, J. F., N. B. Bapela, et al. (2008). "Immune parameters as markers of tuberculosis extent of disease and early prediction of anti-tuberculosis chemotherapy response." J Infect 56(5): 340-7.

Doherty, M., R. S. Wallis, et al. (2009). "Biomarkers for tuberculosis disease status and diagnosis." Curr Opin Pulm Med 15(3): 181-7. 
Eugen-Olsen, J., P. Gustafson, et al. (2002). "The serum level of soluble urokinase receptor is elevated in tuberculosis patients and predicts mortality during treatment: a community study from Guinea-Bissau." Int J Tuberc Lung Dis 6(8): 686-92.

Flores, L., K. Steingart, et al. (2011). "Antigen detection tests for the diagnosis of tuberculosis: A systematic review and meta-analysis." Clin Vaccine Immunol.

Flores, L. L., M. Pai, et al. (2005). "In-house nucleic acid amplification tests for the detection of Mycobacterium tuberculosis in sputum specimens: meta-analysis and metaregression." BMC Microbiol 5: 55.

Fuchs, D., A. Hausen, et al. (1984). "Neopterin as an index of immune response in patients with tuberculosis." Lung 162(6): 337-46.

Goto, M., Y. Noguchi, et al. (2003). "Diagnostic value of adenosine deaminase in tuberculous pleural effusion: a meta-analysis." Ann Clin Biochem 40(Pt 4): 374-81.

Greco, S., E. Girardi, et al. (2003). "Adenosine deaminase and interferon gamma measurements for the diagnosis of tuberculous pleurisy: a meta-analysis." Int J Tuberc Lung Dis 7(8): 777-86.

Greco, S., E. Girardi, et al. (2006). "Current evidence on diagnostic accuracy of commercially based nucleic acid amplification tests for the diagnosis of pulmonary tuberculosis." Thorax 61(9): 783-90.

Harari, A., V. Rozot, et al. (2011). "Dominant TNF-alpha+ Mycobacterium tuberculosisspecific CD4+ $\mathrm{T}$ cell responses discriminate between latent infection and active disease." Nat Med 17(3): 372-6.

Immanuel, C., R. Rajeswari, et al. (2001). "Serial evaluation of serum neopterin in HIV seronegative patients treated for tuberculosis." Int J Tuberc Lung Dis 5(2): 185-90.

Jacobsen, M., D. Repsilber, et al. (2007). "Candidate biomarkers for discrimination between infection and disease caused by Mycobacterium tuberculosis." J Mol Med 85(6): 613-21.

Jafari, C., S. Thijsen, et al. (2009). "Bronchoalveolar lavage enzyme-linked immunospot for a rapid diagnosis of tuberculosis: a Tuberculosis Network European Trialsgroup study." Am J Respir Crit Care Med 180(7): 666-73.

Jiang, J., H. Z. Shi, et al. (2007). "Diagnostic value of interferon-gamma in tuberculous pleurisy: a metaanalysis." Chest 131(4): 1133-41.

Kalantri, S., M. Pai, et al. (2005). "Bacteriophage- based tests for the detection of Mycobacterium tuberculosis in clinical specimens: a systematic review and metaanalysis." BMC Infect Dis 5: 59.

Kandemir, O., B. Uluba, et al. (2003). "Elevation of procalcitonin level in patients with pulmonary tuberculosis and in medical staff with close patient contact." Arch Med Res 34(4): 311-4.

Kikly, K., L. Liu, et al. (2006). "The IL-23/Th(17) axis: therapeutic targets for autoimmune inflammation." Curr Opin Immunol 18(6): 670-5.

Korn, T., E. Bettelli, et al. (2007). "IL-21 initiates an alternative pathway to induce proinflammatory T(H)17 cells." Nature 448(7152): 484-7.

Kunnath-Velayudhan, S., H. Salamon, et al. (2010). "Dynamic antibody responses to the Mycobacterium tuberculosis proteome." Proc Natl Acad Sci U S A 107(33): 14703-8.

Lalvani, A. (2007). "Diagnosing tuberculosis infection in the 21st century: new tools to tackle an old enemy." Chest 131(6): 1898-906. 
Liang, Q. L., H. Z. Shi, et al. (2008). "Diagnostic accuracy of adenosine deaminase in tuberculous pleurisy: a meta-analysis." Respir Med 102(5): 744-54.

Liang, S. C., X. Y. Tan, et al. (2006). "Interleukin (IL)-22 and IL-17 are coexpressed by Th17 cells and cooperatively enhance expression of antimicrobial peptides." J Exp Med 203(10): 2271-9.

Ling, D. I., L. L. Flores, et al. (2008). "Commercial nucleic-acid amplification tests for diagnosis of pulmonary tuberculosis in respiratory specimens: meta-analysis and meta-regression." PLoS One 3(2): e1536.

Liu, C., D. Xu, et al. (2009). "15-Lipoxygenase-1 induces expression and release of chemokines in cultured human lung epithelial cells." Am J Physiol Lung Cell Mol Physiol 297(1): L196-203.

Lonnroth, K. and M. Raviglione (2008). "Global epidemiology of tuberculosis: prospects for control." Semin Respir Crit Care Med 29(5): 481-91.

Lucas, M., P. Nicol, et al. (2010). "A prospective large-scale study of methods for the detection of latent Mycobacterium tuberculosis infection in refugee children." Thorax 65(5): 442-8.

Lyashchenko, K., R. Colangeli, et al. (1998). "Heterogeneous antibody responses in tuberculosis." Infect Immun 66(8): 3936-40.

Maertzdorf, J., D. Repsilber, et al. (2010). "Human gene expression profiles of susceptibility and resistance in tuberculosis." Genes Immun.

Maher, D., C. Dye, et al. (2007). "Planning to improve global health: the next decade of tuberculosis control." Bull World Health Organ 85(5): 341-7.

Marin, N. D., S. C. Paris, et al. (2010). "Regulatory T cell frequency and modulation of IFNgamma and IL-17 in active and latent tuberculosis." Tuberculosis (Edinb) 90(4): 25261.

Mase, S. R., A. Ramsay, et al. (2007). "Yield of serial sputum specimen examinations in the diagnosis of pulmonary tuberculosis: a systematic review." Int J Tuberc Lung Dis 11(5): 485-95.

Metzger, J., T. Kirsch, et al. (2010). "Urinary excretion of twenty peptides forms an early and accurate diagnostic pattern of acute kidney injury." Kidney Int 78(12): 1252-62.

Millington, K. A., S. Gooding, et al. (2010). "Mycobacterium tuberculosis-specific cellular immune profiles suggest bacillary persistence decades after spontaneous cure in untreated tuberculosis." J Infect Dis 202(11): 1685-9.

Moller, M., E. de Wit, et al. (2009). "Past, present and future directions in human genetic susceptibility to tuberculosis." FEMS Immunol Med Microbiol 58(1): 3-26.

National Health Service, U. (2005). The Mantoux test: Administration, reading and interpretation. London, Department of Health Publications: 1-6.

Nyamande, K. and U. G. Lalloo (2006). "Serum procalcitonin distinguishes CAP due to bacteria, Mycobacterium tuberculosis and PJP." Int J Tuberc Lung Dis 10(5): 510-5.

Pai, M., L. L. Flores, et al. (2003). "Diagnostic accuracy of nucleic acid amplification tests for tuberculous meningitis: a systematic review and meta-analysis." Lancet Infect Dis 3(10): 633-43.

Pai, M., J. Minion, et al. (2010). "New and improved tuberculosis diagnostics: evidence, policy, practice, and impact." Curr Opin Pulm Med 16(3): 271-84.

Pai, M., A. Ramsay, et al. (2008). "Evidence-based tuberculosis diagnosis." PLoS Med 5(7): e156. 
Pai, M., L. W. Riley, et al. (2004). "Interferon-gamma assays in the immunodiagnosis of tuberculosis: a systematic review." Lancet Infect Dis 4(12): 761-76.

Pai, M., A. Zwerling, et al. (2008). "Systematic review: T-cell-based assays for the diagnosis of latent tuberculosis infection: an update." Ann Intern Med 149(3): 177-84.

Phillips, M., R. N. Cataneo, et al. (2007). "Volatile biomarkers of pulmonary tuberculosis in the breath." Tuberculosis (Edinburgh, Scotland) 87: 44-52.

Prat, C., J. Dominguez, et al. (2006). "Procalcitonin and neopterin correlation with aetiology and severity of pneumonia." J Infect 52(3): 169-77.

Prevention. (2000). "Diagnostic Standards and Classification of Tuberculosis in Adults and Children. This official statement of the American Thoracic Society and the Centers for Disease Control and Prevention was adopted by the ATS Board of Directors, July 1999. This statement was endorsed by the Council of the Infectious Disease Society of America, September 1999." Am J Respir Crit Care Med 161(4 Pt 1): 137695.

Riquelme, A., M. Calvo, et al. (2006). "Value of adenosine deaminase (ADA) in ascitic fluid for the diagnosis of tuberculous peritonitis: a meta-analysis." J Clin Gastroenterol 40(8): 705-10.

Russell, D. G., C. E. Barry, 3rd, et al. (2010). "Tuberculosis: what we don't know can, and does, hurt us." Science 328(5980): 852-6.

Sarmiento, O. L., K. A. Weigle, et al. (2003). "Assessment by meta-analysis of PCR for diagnosis of smear-negative pulmonary tuberculosis." J Clin Microbiol 41(7): 323340.

Schleicher, G. K., V. Herbert, et al. (2005). "Procalcitonin and C-reactive protein levels in HIV-positive subjects with tuberculosis and pneumonia." Eur Respir J 25(4): 688-92.

Schneider, B. E., D. Korbel, et al. (2010). "A role for IL-18 in protective immunity against Mycobacterium tuberculosis." Eur J Immunol 40(2): 396-405.

Semmo, N., M. Lucas, et al. (2006). "Maintenance of HCV-specific T-cell responses in antibody-deficient patients a decade after early therapy." Blood 107(11): 4570-1.

Shen, Y., L. Shen, et al. (2004). "Clinical latency and reactivation of AIDS-related mycobacterial infections." J Virol 78(24): 14023-32.

Steingart, K. R., N. Dendukuri, et al. (2009). "Performance of purified antigens for serodiagnosis of pulmonary tuberculosis: a meta-analysis." Clin Vaccine Immunol 16(2): 260-76.

Steingart, K. R., L. L. Flores, et al. (2011). "Commercial serological tests for the diagnosis of active pulmonary and extrapulmonary tuberculosis: an updated systematic review and meta-analysis." PLoS Med 8(8): e1001062.

Steingart, K. R., M. Henry, et al. (2007). "Commercial serological antibody detection tests for the diagnosis of pulmonary tuberculosis: a systematic review." PLoS Med 4(6): e202.

Steingart, K. R., M. Henry, et al. (2007). "A systematic review of commercial serological antibody detection tests for the diagnosis of extrapulmonary tuberculosis." Thorax 62(10): 911-8.

Steingart, K. R., M. Henry, et al. (2006). "Fluorescence versus conventional sputum smear microscopy for tuberculosis: a systematic review." Lancet Infect Dis 6(9): 570-81. 
Steingart, K. R., V. Ng, et al. (2006). "Sputum processing methods to improve the sensitivity of smear microscopy for tuberculosis: a systematic review." Lancet Infect Dis 6(10): 664-74.

Thomas, M. M., T. S. Hinks, et al. (2008). "Rapid diagnosis of Mycobacterium tuberculosis meningitis by enumeration of cerebrospinal fluid antigen-specific T-cells." Int J Tuberc Lung Dis 12(6): 651-7.

Thye, T., F. O. Vannberg, et al. (2010). "Genome-wide association analyses identifies a susceptibility locus for tuberculosis on chromosome 18q11.2." Nat Genet 42(9): 73941.

Torrado, E. and A. M. Cooper (2010). "IL-17 and Th17 cells in tuberculosis." Cytokine Growth Factor Rev 21(6): 455-62.

Tufariello, J. M., J. Chan, et al. (2003). "Latent tuberculosis: mechanisms of host and bacillus that contribute to persistent infection." Lancet Infect Dis 3(9): 578-90.

Tuon, F. F., M. N. Litvoc, et al. (2006). "Adenosine deaminase and tuberculous pericarditis--a systematic review with meta-analysis." Acta Trop 99(1): 67-74.

Turgut, T., H. Akbulut, et al. (2006). "Serum interleukin-2 and neopterin levels as useful markers for treatment of active pulmonary tuberculosis." Tohoku J Exp Med 209(4): 321-8.

Vannberg, F. O., S. J. Chapman, et al. (2011). "Human genetic susceptibility to intracellular pathogens." Immunol Rev 240(1): 105-16.

Wallis, R. S., M. S. Helfand, et al. (1996). "Immune activation, allergic drug toxicity and mortality in HIV-positive tuberculosis." Tuber Lung Dis 77(6): 516-23.

Wallis, R. S., M. Pai, et al. (2010). "Biomarkers and diagnostics for tuberculosis: progress, needs, and translation into practice." Lancet 375(9729): 1920-37.

Walzl, G., K. Ronacher, et al. (2008). "Biomarkers for TB treatment response: challenges and future strategies." J Infect 57(2): 103-9.

Weinmann, A. S., P. S. Yan, et al. (2002). "Isolating human transcription factor targets by coupling chromatin immunoprecipitation and CpG island microarray analysis." Genes Dev 16(2): 235-44.

WHO (2006) "The stop TB strategy."

Wolf, A. J., L. Desvignes, et al. (2008). "Initiation of the adaptive immune response to Mycobacterium tuberculosis depends on antigen production in the local lymph node, not the lungs." J Exp Med 205(1): 105-15.

Wright, A., M. Zignol, et al. (2009). "Epidemiology of antituberculosis drug resistance 200207: an updated analysis of the Global Project on Anti-Tuberculosis Drug Resistance Surveillance." Lancet 373(9678): 1861-73.

Wu, X., Y. Yang, et al. (2010). "Humoral immune responses against the Mycobacterium tuberculosis 38-kilodalton, MTB48, and CFP-10/ESAT-6 antigens in tuberculosis." Clin Vaccine Immunol 17(3): 372-5.

Xu, H. B., R. H. Jiang, et al. (2010). "Diagnostic value of adenosine deaminase in cerebrospinal fluid for tuberculous meningitis: a meta-analysis." Int J Tuberc Lung Dis 14(11): 1382-7. 


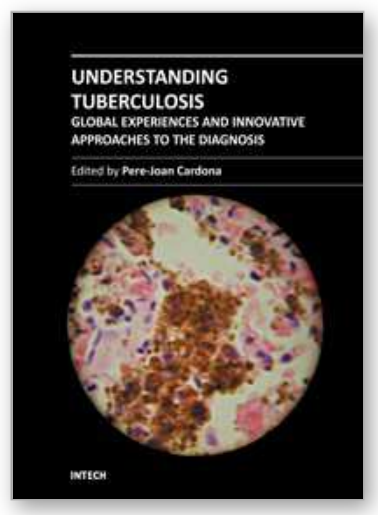

\author{
Understanding Tuberculosis - Global Experiences and Innovative \\ Approaches to the Diagnosis \\ Edited by Dr. Pere-Joan Cardona
}

ISBN 978-953-307-938-7

Hard cover, 552 pages

Publisher InTech

Published online 15, February, 2012

Published in print edition February, 2012

Mycobacterium tuberculosis is a disease that is transmitted through aerosol. This is the reason why it is estimated that a third of humankind is already infected by Mycobacterium tuberculosis. The vast majority of the infected do not know about their status. Mycobacterium tuberculosis is a silent pathogen, causing no symptomatology at all during the infection. In addition, infected people cannot cause further infections. Unfortunately, an estimated 10 per cent of the infected population has the probability to develop the disease, making it very difficult to eradicate. Once in this stage, the bacilli can be transmitted to other persons and the development of clinical symptoms is very progressive. Therefore the diagnosis, especially the discrimination between infection and disease, is a real challenge. In this book, we present the experience of worldwide specialists on the diagnosis, along with its lights and shadows.

\title{
How to reference
}

In order to correctly reference this scholarly work, feel free to copy and paste the following:

Michaela Lucas, Andrew Lucas and Silvana Gaudieri (2012). New Diagnostics for Mycobacterium tuberculosis, Understanding Tuberculosis - Global Experiences and Innovative Approaches to the Diagnosis, Dr. Pere-Joan Cardona (Ed.), ISBN: 978-953-307-938-7, InTech, Available from:

http://www.intechopen.com/books/understanding-tuberculosis-global-experiences-and-innovative-approachesto-the-diagnosis/new-diagnostics-for-mycobacterium-tuberculosis-

\section{INTECH}

open science | open minds

\section{InTech Europe}

University Campus STeP Ri

Slavka Krautzeka 83/A

51000 Rijeka, Croatia

Phone: +385 (51) 770447

Fax: +385 (51) 686166

www.intechopen.com

\section{InTech China}

Unit 405, Office Block, Hotel Equatorial Shanghai

No.65, Yan An Road (West), Shanghai, 200040, China

中国上海市延安西路65号上海国际贵都大饭店办公楼 405 单元

Phone: +86-21-62489820

Fax: $+86-21-62489821$ 
(C) 2012 The Author(s). Licensee IntechOpen. This is an open access article distributed under the terms of the Creative Commons Attribution 3.0 License, which permits unrestricted use, distribution, and reproduction in any medium, provided the original work is properly cited. 